\title{
Characterizing memories of fictional events
}

\begin{tabular}{|c|c|}
\hline $\begin{array}{l}\text { the funda- } \\
\text { mental building } \\
\text { blocks of event } \\
\text { memory are } \\
\text { the same, } \\
\text { regardless of } \\
\text { whether the } \\
\text { source was } \\
\text { from lived } \\
\text { experience ... } \\
\text { or a work of } \\
\text { fiction }\end{array}$ & $\begin{array}{l}\text { Memories for the events of fictional } \\
\text { stories can be just as vivid and } \\
\text { personally important as memories of } \\
\text { autobiographical events, according } \\
\text { to new research published in Journal } \\
\text { of Experimental Psychology: General. } \\
\text { These findings support the idea that } \\
\text { human memory is constructed from } \\
\text { multiple sources. } \\
\text { Memories of autobiographical } \\
\text { events have been well-characterized; } \\
\text { remembering events that happened to } \\
\text { us often involves a sense of travelling } \\
\text { to the past, vivid details, and a } \\
\text { strong belief that the events actually } \\
\text { occurred. However, people can also } \\
\text { recall memories about events that } \\
\text { happened to other people, including } \\
\text { fictional stories in movies, TV shows, } \\
\text { and books. "When I'm seeking } \\
\text { courage or motivation, for example, } \\
\text { I might recall a time I triumphed } \\
\text { over a challenge ... or a time when } \\
\text { a character in a book or movie } \\
\text { overcame their challenge," explains } \\
\text { study lead author Brenda Yang. } \\
\text { Despite the prevalence of memories } \\
\text { of fiction, there has been little work to } \\
\text { date examining this type of memory. } \\
\text { Across three studies, Yang, Deffler, } \\
\text { and Marsh asked participants to }\end{array}$ \\
\hline
\end{tabular}

recall both a memory for an event that happened to themselves and a memory for an event from fiction. Participants were asked to recall events that they thought of often, events associated with a specific cue word, or events from a particular time in their life. Participants then rated various properties of the phenomenology and centrality of each memory separately. For example, participants rated their belief that the memory was accurate, how much they re-experienced the same feelings from the original event, the strength of emotions associated with the memory, and the degree of visual imagery present in the memory. They also reported whether the event influenced their identity, whether it helped them to understand themselves and/or their relationships, and other aspects of the personal importance of the memory. These rating scales are standard tools for evaluating autobiographical memories, but their application to memories of fiction was novel.

The researchers found that although memories of fiction were sometimes less vivid or less

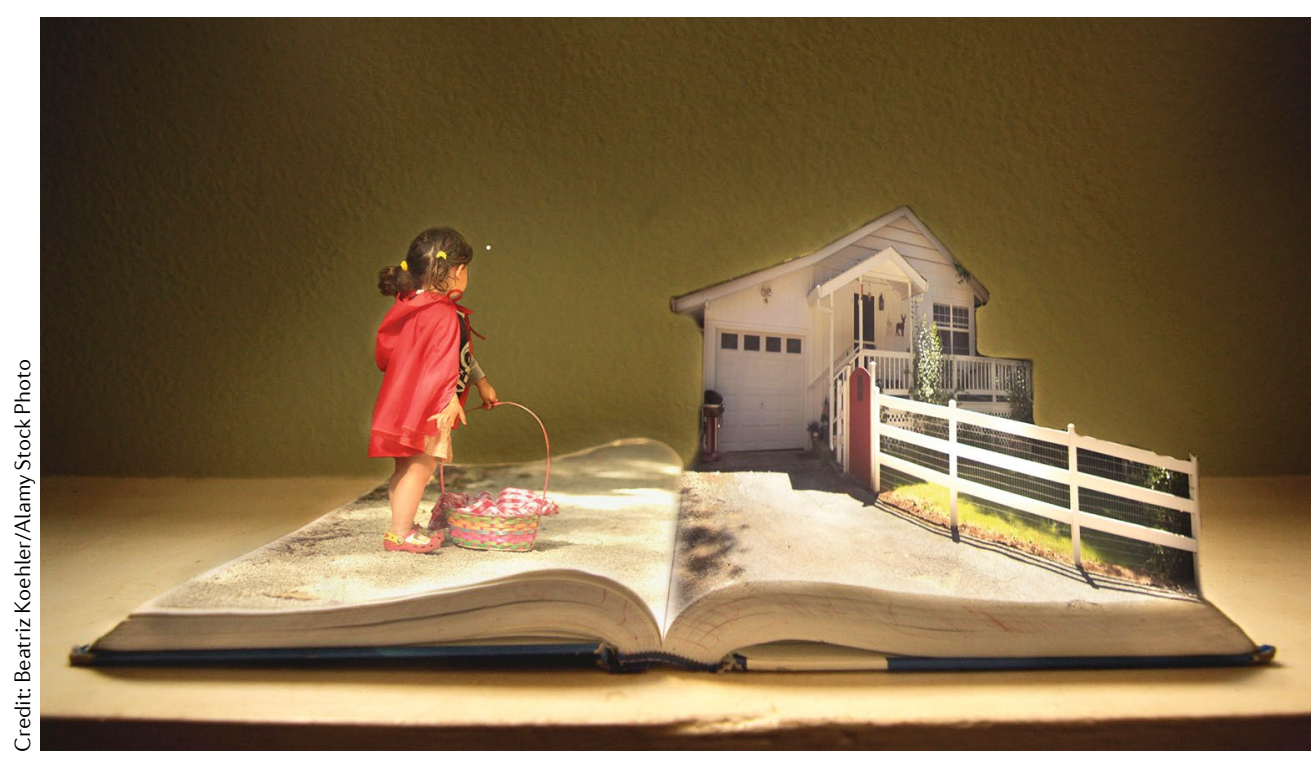

personally significant than memories of autobiographical events, in other cases participants' memories were rated as equally vivid and significant. These results suggest that autobiographical event memories and memories of fiction differ in degree, not kind. "We think the fundamental building blocks of event memory are the same, regardless of whether the source was from lived experience, imagination, someone's retelling, or a work of fiction," explains Yang. This similarity across types of event memory has implications for understanding the constructive and re-constructive nature of memory.

Memories of fiction also have some unique properties that suggest new avenues to understand human memory. Unlike autobiographical events, events of fiction can be re-experienced, which might affect how these memories change over time. Furthermore, memories of fictional events are nested within autobiographical memories. For example, one can remember the fictional events of a movie and also where and with whom one watched the movie. This structure enables a potential dissociation between memories of fiction and of personal events from the same time period.

The researchers conclude that memories of fiction play a key role in human memory by helping to define personal identity and that they deserve future study. "The worlds we depict in fiction have consequences", says Yang. "They form event memories, and ones which we can share together at scale with millions of other people. They help inform how we understand the world."

Teresa Schubert 